\title{
MATHEMATICAL MODELS FOR PREDICTION OF SAFETY FACTORS FOR A SIMPLY SUPPORTED STEEL BEAM
}

\author{
A. U. Barambu1 ${ }^{1}$, M. T. Abdulwahab ${ }^{2,}$ and 0. A. U. Uche ${ }^{3}$ \\ 1,2,3 DePARTMENT OF Civil EnginEERING, BAYERo University Kano, KANO STATE, NIGERIA, \\ E-mail addresses.1 habubarambu@yahoo.com, ${ }^{2}$ amtaytechnology@yahoo.com \\ 3 okoauche@yahoo.co.uk
}

\begin{abstract}
The reliability-based calibration of safety factors for the design of a simply supported steel beam, based on BS5950 (2000) is presented in this research work. The calibration was undertaken using a specialized computer program in Microsoft excel environment developed by the Joint Committee for Structural Safety (JCSS) CODE-CAL 2001. The design variables considered were modeled using the software, and the safety factors for the material, dead and live load were calibrated by varying the safety index. From the results obtained, mathematical prediction models were developed using a least square regression analysis for bending, shear and deflection modes of failure considered in the study. The results showed that the safety factors for material, dead and live load are not unique, but they are influenced by safety index and it was also shown that the safety factors for material, dead and live load vary from 0.61 to $1.15,1.44$ to 1.91 and 1.40 to 1.65 respectively for both bending and shear modes of failure. For deflection mode of failure, the results showed that the safety factors for material, dead and live load vary from 1.08 to $1.56,1.10$ to 1.17 and 0.83 to 1.25 respectively for target safety index $\left(\beta_{t}\right)$ of 2.0 to 4.5 . The mathematical prediction models developed for both bending and shear modes of failure are the same. Therefore, it is recommended that the mathematical prediction models developed in this study for bending and deflection modes of failure could be used when designing a simply supported steel beam to BS 5950 (2000).
\end{abstract}

Keywords: reliability, code calibration, load factor, safety factor, design, steel beam.

\section{INTRODUCTION}

All aspects of structural design have some degree of uncertainty and therefore a safety factor is needed [1]. The safety factor, also known as factor of safety was described by [2] as a comparison for the ratio of the allowable strength to the applied stress. However, by considering a safety factor, yet the variations of load (or structural resistance), distribution factor or changes of load probability density will introduce different failure probabilities, which indicate that safety factors do not always account for the uncertainties existing within the load or even material properties. In some cases however, a smaller safety factor than unity may even handle the uncertainties due to failure probability, as well fulfilling economical purposes [3].

This study aims at mathematical prediction models for safety factors for the design of a simply supported steel beam using regression analysis.

\section{THEORETICAL CONCEPTION}

All quantities (except physical and mathematical constant) that are used in engineering design and calculations are actually associated with some degree of uncertainty [1]. This fact is reflected in the recommendations of current and previous codes of practice, which require that a factor of safety that is much greater than 1 should be adopted. Therefore, structural reliability involves the use of statistical methods to predict the safety of a structure by analyzing the uncertainties involved in the performance of that structure.

For the past several years, structural performance has always been measured by the use of a factor of safety approach in design [4]. As long as the strength of a component exceeds the stress on it, safety is conjectured. But, then, the larger the gap that exists in the strength-stress interference, the greater the reliability and of course, the heavier a structure becomes. Conversely, the smaller the gap, the lower the

\footnotetext{
* Corresponding author tel: + 234-806-649-6979
} 
reliability, but the lighter the structure too [4]. There is also the possibility of a safety factor being too large or too small in a design in spite of the historical success of the philosophy. In order to offer a structure that is neither too heavy nor too light and at the same time satisfy a target reliability while counting for randomness in the intervening variables, full probabilistic thinking has been described as a good explicit [5].

\subsection{Regression Analysis}

Regression analysis is the most widely used of all statistical techniques: it is the study of linear, additive relationships between variables. Let $\mathrm{Y}$ denote the "dependent" variable whose values you wish to predict, and let $\mathrm{X}_{1}, \ldots, \mathrm{X}_{\mathrm{k}}$ denote the "independent" variables from which you wish to predict it, with the value of variable $X_{i}$ in period $t$ (or in row $t$ of the data set) denoted by $X_{i t}$. Then the equation for computing the predicted value of $\mathrm{Y}_{\mathrm{t}}$ is given as:

$$
\hat{\mathrm{Y}}_{t}=b_{0}+b_{1} X_{1 t}+b_{2} X_{2 t}+\cdots+b_{2} K_{2 t}
$$

This formula has the property that the prediction for $\mathrm{Y}$ is a straight-line function of each of the $\mathrm{X}$ variables, holding the others fixed, and the contributions of different $\mathrm{X}$ variables to the predictions are additive. The slopes of their individual straight-line relationships with $\mathrm{Y}$ are the constants $b_{1}, b_{2} \ldots b_{k}$, which represent the coefficients of the variables. That is, $b_{i}$ is the change in the predicted value of $Y$ per unit of change in $X_{i}$, other things being equal. The additional constant $b_{0}$, which represent intercept, is the prediction that the model would make if all the X's were zero (if that is possible). The coefficients and intercept are estimated by least squares, i.e., setting them equal to the unique values that minimize the sum of squared errors within the sample of data to which the model is fitted; and the model's prediction errors are typically assumed to be independently and identically normally distributed.

\section{MATERIALS AND METHODS}

In this study, a simply supported symmetrical I-beam to support $150 \mathrm{~mm}$ thick concrete slab for a library structure was used in the analysis. The beam was subjected to a dead load of $3.53 \mathrm{kN} / \mathrm{m}$ and an imposed load of $4.0 \mathrm{kN} / \mathrm{m}$ and the deterministic design was then carried out in accordance to BS5950 (2000), and $457 \times 152 \times 67$ UB to satisfy the code design criteria for bending, shear and deflection. The section is therefore adopted for the reliability analysis and calibration of the safety factors using JCSS Code-Cal Software and then regression analysis to develop the mathematical models.
Using optimization methods Code-Cal was also used to determine partial safety and load combination factors corresponding to a predefined safety level, whereby up to three materials can be considered at the same time. The free-body diagram of the beam as well as beam cross-section are presented in Figures 1 and 2 respectively.

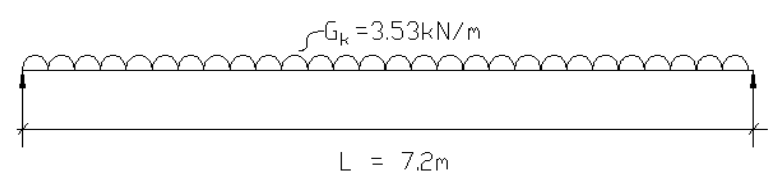

(a)

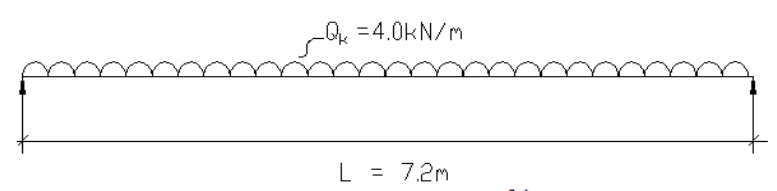

(b)

Figure 1: Free body diagram of simply supported steel beam

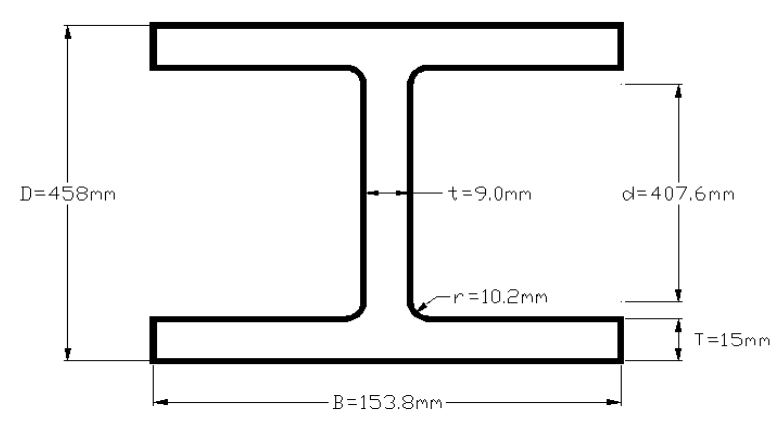

Figure 2: Cross-section of the simply supported steel beam

\subsection{Development of the Limit State Functions}

The limit state functions for bending, shear and deflection failure modes were developed and given as Equations (2) to (4):

\section{Bending mode of failure}

$$
G_{(x)}=M_{u}-M_{A}=p_{y} S_{y}-\frac{\left(y G_{k}+y Q_{k}\right) L^{2}}{8}
$$

Shear mode of failure

$$
G_{(x)}=0.6 p_{y} A_{v}-\frac{\left(y G_{k}+y Q_{k}\right) L}{2}
$$

\section{Deflection mode of failure}

Where

$$
G_{(x)}=\frac{L \times 1000}{360}-\frac{5 \gamma Q L^{4}}{384 E I \times 10^{4}}
$$

$G_{k}$ is the dead loa, $Q_{k}$ is the imposed load, $M_{u}$ is the ultimate moment, $M_{A}$ is the applied moment, $p_{y}$ is the design yield strength, $S_{y}$ is the section modulus and $L$ is the length of the beam. 


\section{RESULTS AND DISCUSSIONS}

Based on the results of the calibrated safety factors obtained, mathematical prediction models were developed using regression analysis on Microsoft excel 2007. The developed models are presented in Table 1 for bending, shear and deflection modes of failure. Also the least square regression plots for material, dead and live load factors of safety are presented in Figure 3 to 11 respectively for bending, shear and deflection mode of failure. The prediction models in Table 1 show that the parameters considered in bending, shear and deflection modes of failure are non-linear.

From Figure 3 and $4, \gamma_{\mathrm{m}}=0.045 \beta_{\mathrm{t}}{ }^{2}-0.073 \beta_{\mathrm{t}}+0.582$ and $\gamma_{\mathrm{G}}=-0.036 \beta_{\mathrm{t}}{ }^{2}+0.042 \beta_{\mathrm{t}}+1.953$ were developed as the prediction models in bending mode of failure respectively and the co-efficient of determination for each model is 0.994 . Whereas, prediction model, $\gamma_{Q}=-$ $0.037 \beta_{\mathrm{t}}^{2}+0.318 \beta_{\mathrm{t}}+0.943$ was developed from figure 5 , with 0.827 as the co-efficient of determination, where $\beta_{\mathrm{t}}$ is the desired safety index.

Table1: Mathematical Prediction Models for the Safety Factors for Bending, Shear and Deflection modes of Failure

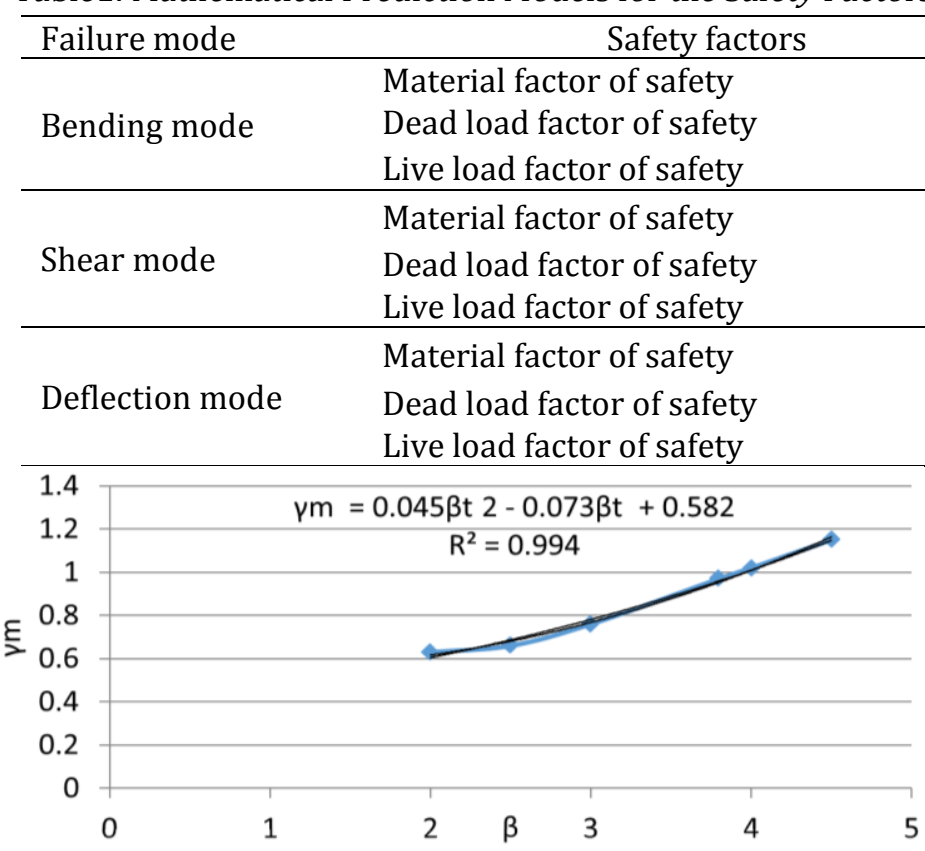

Figure 3: Material safety factors against safety indices (bending mode)

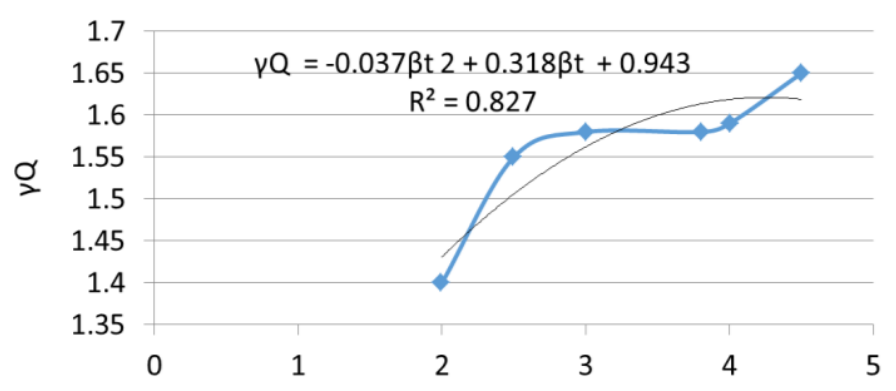

Figure 5: Live load factors of safety against safety indices (bending mode)

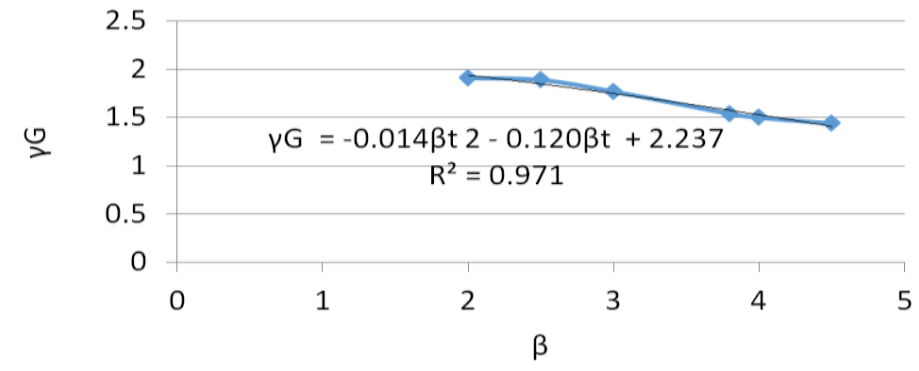

Figure 7: Dead load factors of safety against safety indices (shear mode)

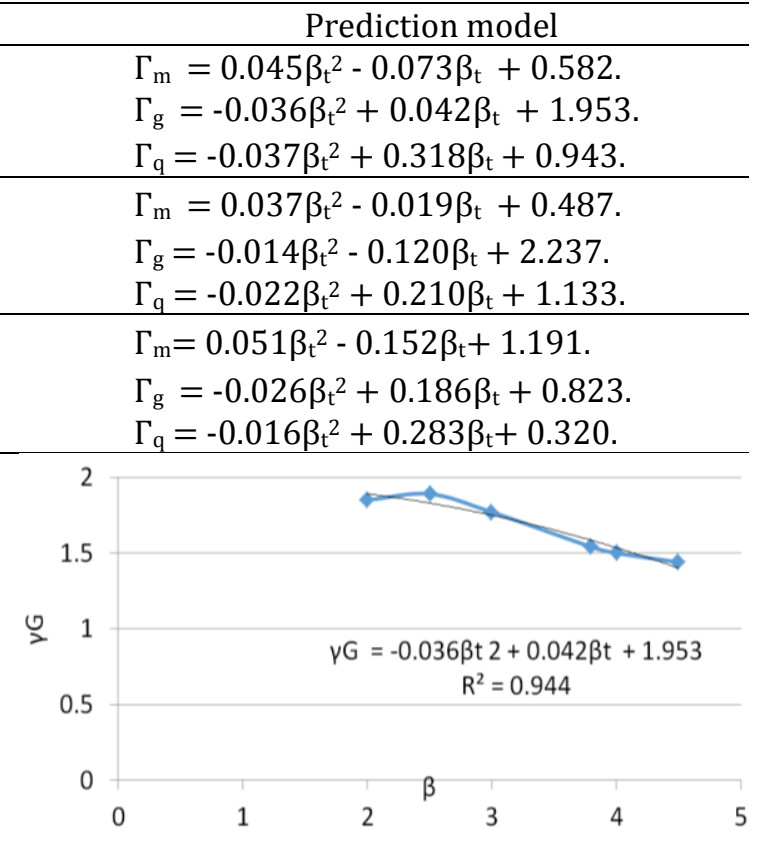

Figure 4: Dead load factors of safety against safety indices (bending mode)

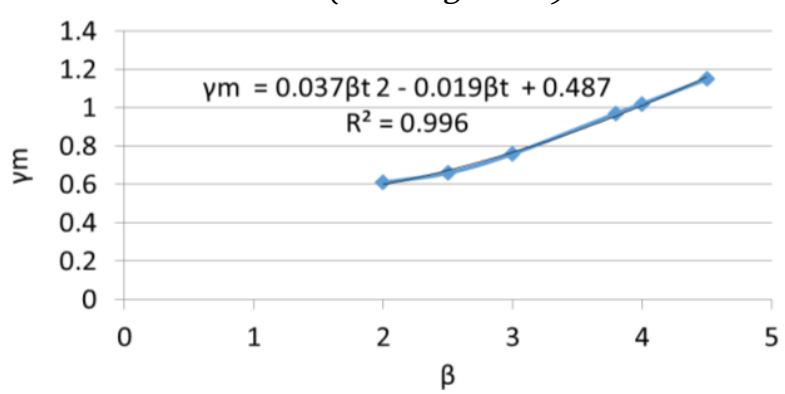

Figure 6: Material factors of safety against safety indices (shear mode)

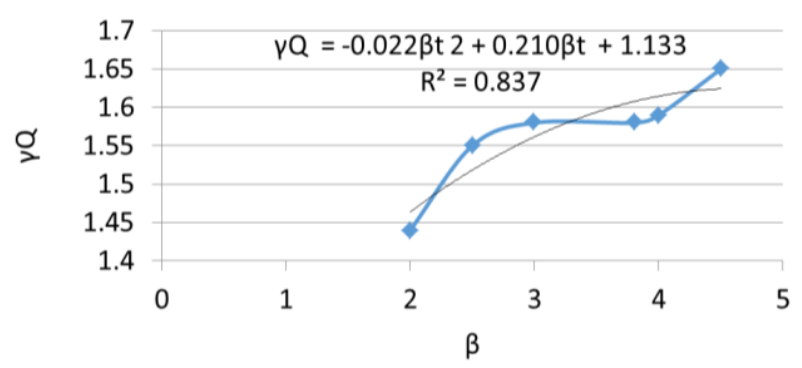

Figure 8: Live load factors of safety against safety indices (Shear mode)

Vol. 36, No. 4, October 2017 
It was observed that, the prediction models developed from Figures 6,7 and 8are non-linear for material, dead load and live load factors and resulted to $\gamma_{\mathrm{m}}=0.037 \beta_{\mathrm{t}}^{2}$ - $0.019 \beta_{\mathrm{t}}+0.487$ with co-efficient of determination of 0.996; $\gamma_{\mathrm{G}}=-0.014 \beta_{\mathrm{t}}^{2}-0.120 \beta_{\mathrm{t}}+2.237$ with co-efficient of determination of 0.971 and $\gamma_{Q}=-0.022 \beta_{\mathrm{t}^{2}}+0.210 \beta_{\mathrm{t}}$ +1.133 with co-efficient of determination of 0.837 respectively, where $\beta_{\mathrm{t}}$ denotes the desired safety index.

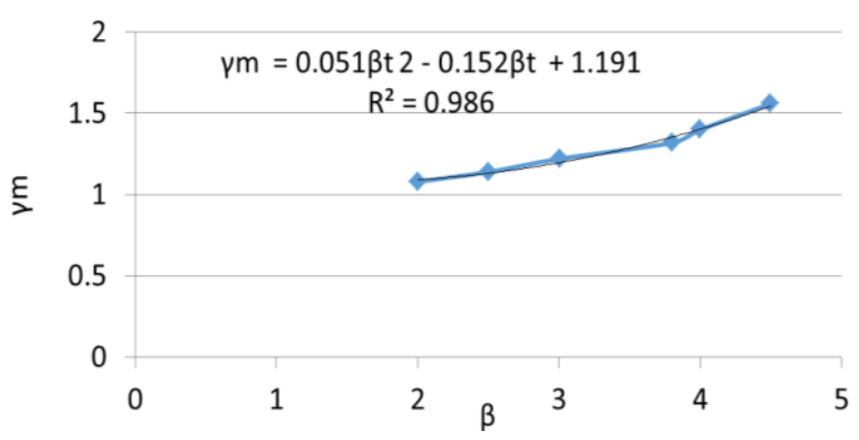

Figure 9: Material factors of safety against safety indices (Deflection mode)

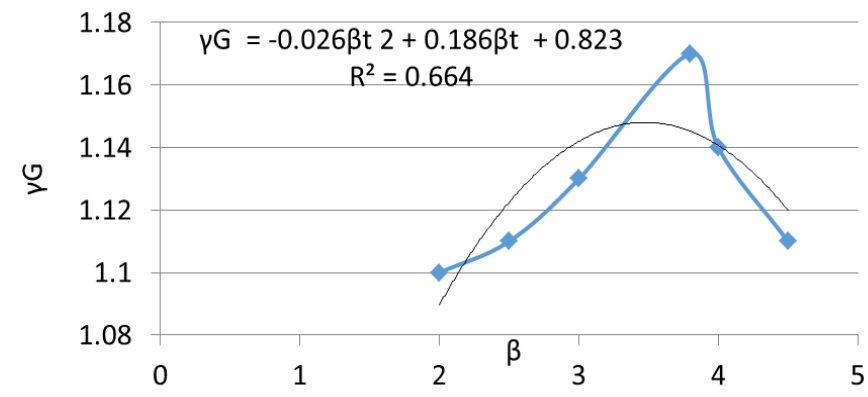

Figure 10: Dead load factors of safety against safety indices (Deflection mode)

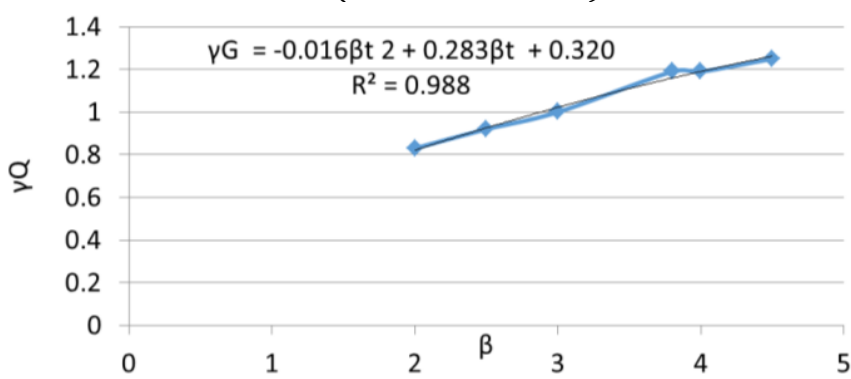

Figure 11: Live load factors of safety against safety indices (Deflection mode)

It was also recorded that, the prediction models developed from Figures 9,10 and 11 for material, dead load and live load factors are $\gamma_{\mathrm{m}}=0.051 \beta_{\mathrm{t}}^{2}-0.152 \beta_{\mathrm{t}}+$
1.191 with co-efficient of determination of $0.986 ; \gamma_{\mathrm{G}}=-$ $0.026 \beta_{\mathrm{t}}{ }^{2}+0.186 \beta_{\mathrm{t}}+0.823$ with co-efficient of determination of 0.664 and $\gamma_{\mathrm{Q}}=-0.016 \beta_{\mathrm{t}}^{2}+0.283 \beta_{\mathrm{t}}+$ 0.320 with co-efficient of determination of 0.988 respectively. This shows that the prediction models are non-linear.

\section{CONCLUSIONS}

Based on the calibration results in this study, the following conclusions were made

1. There is no noticeable difference in the calibrated safety factors results for both bending and shear modes of failure, therefore any of the prediction model adopted, can be used to account for both bending and shear modes of failure with exception for $\beta_{\mathrm{t}}=2.0$.

2. The safety factors for material, dead and live loads for bending, shear and deflection modesof failure are not unique.

3. The safety factors for material, dead and live loads for bending, shear and deflectionmodesof failure are influenced or affected by the required safety levels (target safety index).

\section{REFERENCES}

[1] Mohammed, J. K. Reliability-Based Analysis and Calibration of Eurocode 5 design criteria for a solid timber portal frame. PhD. thesis. Department of Civil Engineering, Ahmadu Bello University, Zaria. 2013.

[2] Ullman, D. G. The Mechanical Design Process, Third Edition, The McGraw-Hill Companies, Inc, New York, 2003.

[3] Ghasemi, M. R. and Yousefi, M. Reliability-based Optimization of Steel Framed Structures Using Modified Genetic Algorithm. Asian Journal of Civil engineering (Buildings and Housing). 12(4): pp. 449-475, 2011.

[4] Ditlevsen, O. and Madsen, H. O. Structural Reliability Methods. John Wiley \& Sons, Chichester, 2005.

[5] Andre, T. B. and Antonio, C. S. A First Attempt Towards Reliability-based Calibration of Brazilian Design Codes. J. of the Braz. Soc. of Mech. Sci. \& Eng. XXXII (2). pp 119-127, 2010. 